\title{
Content-Based or Research-Driven? An Empirical Case Study of Attitudes toward Adult Education in an American Graduate School
}

\author{
Joshua D. Reichard \\ Oxford Graduate School \\ American Centre for Religion and Society Studies \\ United States
}

Received: March 21, $2011 \quad$ Accepted: March 27, $2012 \quad$ Published: May 1, 2012

doi:10.5296/jse.v2i2.1543ＵRL: http://dx.doi.org/10.5296/jse.v2i2.1543

\begin{abstract}
This study comprises a critical comparison of graduate school student and instructor attitudes toward content-based and research-driven graduate school education. The study consisted of a literature review related to adult learning theory followed by the development of a conceptual framework for graduate school education based on the relevant literature. The study included the development of a survey instrument that correlated with the conceptual framework. The first eight items on the instrument related directly to the eight categories presented in the review of literature: metacognition versus memorization, critical thinking versus repetition, interdisciplinary versus disciplinary, and technology-integrated versus technology-independent. The survey was administered to a sample of graduate school students in a single institution ( $\mathrm{n}=103)$. The instrument was scored by totaling the values in two categories: content-based and research-driven. Three hypotheses were tested. The findings indicated that while graduate school students and instructors both valued research-driven instruction over content-based instruction, perceptions concerning the actualities of instruction were found to be statistically significantly different. In light of the findings, the conclusion includes recommendations for reform in similar graduate school contexts.
\end{abstract}

Keywords: Graduate education, Adult learning, Research methods, Interdisciplinary studies 


\section{Introduction and Problem Statement}

\subsection{Problem statement}

Graduate students have specific needs related to their professional and academic goals. However, these needs are often overlooked by instructors and the teaching and learning process devolves into methods utilized for younger students. The foremost of such methods is an overemphasis on content rather than research. Graduate students are presented content-laden syllabi or pre-determined textbooks that are intended to lead to specific learning outcomes. The problem with such an approach is that graduate students are not seeking to memorize content; they are seeking to investigate problems relevant to their needs with the goals of developing broader, more general skills such as metacognition, critical thinking, interdisciplinary studies, and technology-assisted research. Instructors anecdotally refer to "critical thinking" and "higher order thinking" without considering the implications of actually integrating the strategies for developing critical thinking into the curriculum (Willingham, 2007). There is thereby a deficit between what is presented to graduate students in terms of content-based learning and the ultimate goals that graduate students pursue in terms of research-driven learning.

Graduate students do not seek to memorize facts; they desire a "deep learning” experience that encompasses general skills they can apply to their profession and to their academic life. Wilson-Smith \& Colby (2007) presented an approach to teaching that intentionally fosters deep learning. The objective was to demonstrate that instructors can adopt either a surface or deep approach to teaching which has direct implications on whether or not students have a deep or surface learning experience. Unfortunately, when courses in graduate school are content-heavy, they merely foster surface learning rather than deep learning. This study was intended to investigate the attitudes of graduate students and their associated instructors toward either content-based or research-driven graduate education. The goal of this empirical case study was to determine whether or not students and instructors agree that the curricula they are teaching and learning is content-based or research driven. The findings may be utilized to lead curricular reform that fosters the values of the students and the intentions of the instructors.

\subsection{Research Question}

The following question forms the basis of this study: How do attitudes toward content-based instruction and research-driven instruction differ between graduate students and instructors in graduate school?

\section{Review of Literature}

\subsection{Foundations}

\subsubsection{Characteristics of Adult Education}

The central argument of this study is concerned with the nature of adult learners. Traditional pedagogical strategies that are successful in primary, secondary, and college-level classroom settings do not translate well to teaching and learning for adult learners in graduate school. 
Because graduate students are rarely traditional college-age students, methods must be adapted to meet the needs of adult learners, many of whom are in mid-career transition or seeking bi-vocational skills. Traditional pedagogical methods tend to award academically competent students within the social institution of the "school", but adults who are often far removed from traditional forms of formal school, seek affirmation in the "outside”, working world. Within a pedagogical framework, institutions tend to pay less attention to the "rich diversity of talents which make up a person” (Reid, 1978, p. 31) and thereby fail to meet the needs of working adults, for whom pedagogical methods do not always lead to learning.

However, the general tendency toward treating adults as "big children” (Lee, 1998, p. 47) can be addressed through specifically adult-oriented teaching methods that emphasize meeting the needs of graduate students. For adult learners, graduate school reflects a desire for lifelong learning. Therefore, lifelong learning for midlife and older adults should "accommodate both highly individualized, small group as well as traditional, large group" models (Manheimer, 2008, p. 113). Ultimately, two aspects of adult learning should be taken into consideration for adult learners in graduate school: self-direction and co-participation.

Adult education theorist Malcolm Knowles (1984) argued that adults have a deep psychological need for self-direction. According to adult education theory, adults possess the necessary general competence to be self-directed and to meet their own goals throughout the learning process. For adult learners, "being self-directed requires its own set of skills" (Cranton, 1994). Graduate schools should consider such self-direction when designing courses for adult learners.

However, successful adult education programs should focus on more than the career goals of the learner: focus on social and psychological growth is also necessary (Donlevy, 1998, p. 1). Smith (1983) suggested that adults seek learning experiences consistent with their individual preferences for learning; in other words, adults learn what they want to learn, not what they are taught. Adults who are drawn to graduate school voluntarily seek to demonstrate their competency in subjects that interest them and meet their socio-psychological needs. Self-direction can be facilitated by allowing adults to approach learning within the context of individual preferences. Instructors should bear in mind that the "goals pursued by older learners are also diverse, ranging from acquiring specific skills to enriching personal growth and social networking” (Manheimer, 2008, p. 111).

Further, adults attain educational goals through "co-participation" in the process of skill development, through collaboration with their peers in the context of a particular work environment (Billett, 2004, p. 197). Such cooperation erodes the artificial divisions between teacher and learner, allowing the graduate student to contribute to the learning process. Hammond and Collins (1991) noted that a self-directed, co-participative model for adult education ensures that both the learner and the educator share control of the learning process. Therefore, as instructors teach adults in graduate school, they also become co-participators with the learners, resulting in a holistic learning environment that is as much constructed by the learner as by the educator. Learning occurs not only by mastering subject matter or specific skills, but self-directing and co-creating the learning process as well. 


\subsection{Conceptual Framework}

\subsubsection{Graduate Education as Research-driven versus Content-based}

According to Bruce \& Bishop (2002), traditional modes of learning are often "inadequate for coping with these changes or building upon the students' diverse and rich personal backgrounds" (p. 706). The authors conducted a study to determine which aspects of technology-integrated, research-driven instruction were successful in developing appropriate skills in learners. Taxonomies and architectures can guide instructors toward structuring learning in such a way as to facilitate deep learning and research (Wilson-Smith \& Colby, 2007). The categories in the taxonomy below represent alternative approaches to traditional methods of teaching and learning; each proposition represents a content-based approach versus the research-driven approach to graduate school education.

\subsubsection{Transformative versus Transmissive}

First, research-driven graduate school education must be transformative rather than transmissive. Traditionally "top down" approaches to teaching, such as instructors lecturing while students listen, tend to be less effective methods for reaching adult learners (Jerram, 2003). When instructors only articulate surface outcomes it tends to significantly "limit students” (Wilson-Smith \& Colby, 2007, p. 106). Bolkan \& Goodboy (2009) argued that teaching is more than the mere transmission of information, it is a skilled task (p. 296). Instructors who employ the "transmissive teaching philosophy of unilateral communication and lecturing” have been largely ineffective (Bolkan \& Goodboy, 2009, p. 299).

Moreover, Bolkan \& Goodboy conducted a quantitative study involving 165 students who reported on their instructors' leadership in addition to their own classroom behavior and learning. The study employed a series of survey instruments, including the transformational leadership survey developed by Burns (1978). Bolkan \& Goodboy argued that "using transformational leadership, instructors can positively influence student behaviors and perceptions” (p. 296). While Bolkan \& Goodboy recognized that extensive research has been conducted on transformational leadership, they argue that it has been in the context of organizational behavior rather than "traditional student learning outcomes" (p. 297). The series of instruments that Bolkan \& Goodboy employed were intended to assess the three primary factors of transformational leadership: charisma, individual consideration, and intellectual stimulation (p. 297). The authors thereby contended that by employing these principles of transformational leadership in the classroom, "students should report increases in traditional learning outcomes when they perceive their instructors as transformational" (Bolkan \& Goodboy, 2009, p. 297). The experimental component consisted of two primary hypotheses, both of which were supported by the data analysis, which indicated a "moderate to strong positive relationship" between achieving learning outcomes and transformational teaching (p. 301). Thus, Bolkan \& Goodboy suggested that when students "do indeed perceive instructors as transformational leaders" they report greater "learning and participation along with perceptions of teacher credibility” (p. 304). Moreover, Bolkan \& Goodboy concluded that transformational leaders will exhibit a progressive teaching philosophy: that of "admiration, motivation, empowerment, and intellectual stimulation" (p. 
299). This approach is contrary to the traditional methods of education, which tend to perpetuate transmissive knowledge dissemination rather than transformational learning.

\subsubsection{Creativity versus Facts and Details}

Second, research-driven graduate school education should foster creativity rather than focus on facts and details. Willingham (2007) argued against the "narrowing of ideas" that occurs when students focus too heavily on the surface structure and not on the underlying structure of the problem (p. 85). To overcome this dilemma, graduate students must be aware of two factors: familiarity with the problem's deep structure, and knowledge that one should look for deep structure (p.86).

Wallas (1926) was one of the first researchers to describe a creative process. Wallas' model consisted of five stages: preparation, incubation, intimation, illumination, and verification. Preparation is the stage wherein the problem is explored and the human mind is focused, incubation is the stage wherein the problem is internalized into the unconscious dimensions of the human mind, intimation is the stage wherein a sensation develops that orients the mind toward a solution, illumination is the stage wherein a solution becomes a conscious insight in the mind, and finally, verification is the stage wherein the solution is evaluated and applied to the problem. The incubation and verification stages of Wallas' model are perhaps the most important aspects of the creative process. Incubation allows for adequate reflection and verification allows for critical evaluation as to whether or not the solution will work (Wallas, 1926, pp.52-54). Further, Wallas argued that "the stage of incubation should include a large amount of actual mental relaxation” (p. 95). Thus, Wallas concluded that the intelligent person can "put [his or her] mind on to chosen subjects, and turn [his or her] mind off" (p. 92) to allow the incubation of ideas to work. Creativity is critical to a research-driven approach to graduate school education.

Sternberg and Lubart (1995), however, noted that if novelty is the primary factor identifying creativity, it must also exhibit appropriateness. Further, Perkins (1988) defined creativity as follows: “(a) a creative result is a result both original and appropriate, (b) A creative person - a person with creativity - is a person who fairly routinely produces creative results" (p. 311). Caroll (1993) described creativity as the ability to produce original and "remotely associated, clever, or uncommon responses” (p. 395). Thus most definitions of creativity include novelty, appropriateness, and critical thinking.

Graduate students must learn to "work with multiple sources and media, not just a textbook" (Bruce \& Bishop, 2002, p. 707). A community of research is an important part of developing a research-driven approach to learning. According to Bruce \& Bishop (2002), a successful research community is not one in which there is universal conformity, but one that “accommodates plurality and difference” (p. 719). In order to bolster deep learning and creativity, Wilson-Smith \& Colby (2007) recommended utilization of a specific taxonomy as a method of evaluating student assignments developed with an intention toward deep learning and creativity. Wilson-Smith \& Colby presented a table that documents the characteristics of possible student responses corresponding to various levels (Wilson-Smith \& Colby, 2007, p. 108). Deep learning requires collegial dialog to determine which deep outcomes should be 
part of the learning process (Wilson-Smith \& Colby, 2007, p. 106). Allowing students to be co-creators of learning, even in determining learning outcomes, is essential to deep learning and creativity.

\subsubsection{Metacognition versus Memorization}

Third, research-driven graduate school education should focus on teaching the skill of metacognition rather than memorization of facts. In traditional education, the role of the teacher is to "manage the delivery of this knowledge, and the role of the learner is to absorb as much as possible” (Bruce \& Bishop, 2002, p. 706). Wilson-Smith \& Colby (2007) found that the majority of instructors can be characterized by "reproduction or categorization of information or replication" (p. 104). In other words, instructors tend to require students to memorize, categorize, and replicate specific content. Focus is placed on content rather than on research. Further, Marton and Säljö (1976) noted that surface learning does not include intentional reflection; information is simply memorized and perhaps repeated, but never given time for reflection (p. 105).

Willingham (2007) formulated three conclusions: first, that critical thinking is not a skill (p. 15), second, that "there are metacognitive strategies that, once learned, make critical thinking more likely" (p. 16), and third, that critical thinking "depends on domain knowledge” (p. 16). Further, Willingham concluded that students and instructors alike should be aware of the metacognitive process, the regulation of thinking when approaching a particular subject or problem. Metacognitive strategies such as “looking for a problem's deep structure” and "considering both sides of an issue" are central to deep knowledge and critical thinking. Within particular disciplines, students have "context clues to help them figure out which metacognitive strategy to use" and therefore instructors must carefully determine which "domain knowledge they must teach to enable students to do what the strategy calls for" (Willingham, 2007, p. 13). Ultimately, the utilization of critical thinking through metacognition, rather than memorization of detailed content, should be one of the end goals of graduate school education.

\subsubsection{Critical Thinking versus Repetition}

Fourth, research-driven graduate school education should promote critical thinking rather than repetition of content. Wilson-Smith \& Colby (2007) surveyed a sample of instructors in two categories: national board certified and non-board certified to determine if there was significant difference between board certified instructors and non-board certified instructors in terms of their intentional development of learning objectives that foster deep learning and critical thinking. While they found that a majority of instructors aimed instruction at surface learning outcomes, the majority of instructors did not aim toward deep learning regardless of certification status (Wilson-Smith \& Colby, p. 104). Instead, both categories of instructors tended to focus on instruction at the surface, requiring students to memorize and repeat information rather than leading them to deep-learning experiences.

Further, Wilson-Smith \& Colby (2007) divided their initial sample into two groups and asked two primary questions: "Does national board certification elicit deeper responses than 
instructors who attempted board certification but did not achieve it?", and "Do national board instructors develop instruction and structure class assignments designed to produce deeper responses?”. The authors then proceeded to elaborate on their findings in light of a critical thinking taxonomy (Wilson-Smith \& Colby, p. 105) with a working definition of deep learning. The authors framed the an instructional architecture in terms of three surface categories (prestructual, unistructural, and multistructual) and two deep categories (relational and extended abstract). Similarly, Willingham (2007) argued that critical thinking is not a skill that can be taught, rather, it must emerge as part of the learning process. Therefore, instruction must be aimed at fostering critical thinking and deep learning rather than the repetition of mere surface content. Bruce \& Bishop (2002) suggested that in today's complex, globalized world, students must "learn how to learn, and they must ask (find problems), investigate (multiple sources/media), create (engage actively in learning), discuss (collaborate and debate), and reflect” (p. 708). Such categories are important skills for graduate students to develop and refine.

Moreover, Willingham (2007) argued that in general, education tends to focus on a problem's surface structure” (p. 9), but "with deep knowledge, thinking can penetrate beyond surface structure" (p. 10). However, such learning depends on some prior surface-level content knowledge. For example, by exploring the relationship between scientific thinking and scientific knowledge, Willingham argued that scientific thinking depends on scientific knowledge; that is, some domain knowledge is prerequisite to deep scientific thinking, although emphasis cannot remain on the domain knowledge itself (p. 13). Therefore, content knowledge is a prerequisite to critical thinking in any discipline; Willingham utilized science as the discipline of choice.

Although Willingham concluded that teaching students to think critically is a difficult enterprise, he did not conclude that it is impossible. Willingham noted that students are often able to think critically in a particular situation but not in another; this is due to a difference in surface knowledge and deep knowledge of a particular subject. Willingham lamented that instructors "try to teach critical thinking devoid of factual content" (p. 8), a mistake that makes critical thinking programs of "modest benefit" (p. 11). Such a perspective is conducive to graduate education, where students possess prior disciplinary knowledge.

Questioning may be an effective strategy that leads to critical thinking in graduate school education. While domain knowledge is important, instructors must ask the appropriate questions to lead students to the critical thinking process. Nilson (2010) outlined discussion questions such as the McKeachie (p. 140), Brookfield, and Preskill (p. 141) categories. These types of questions are designed to intentionally lead students to critical thinking and thus, to research. Nilson also noted poor questioning techniques; that is, questions that may be at best useless or at worst, intimidating to students (pp. 142-143). Such questions focus on repetition of content-knowledge rather than critical thinking about content-knowledge.

\subsubsection{Interdisciplinary versus Disciplinary. Interdisciplinary Versus Disciplinary}

Fifth, research-driven graduate school education should emphasize broad interdisciplinary thinking rather than narrow disciplinary thinking. Interdisciplinary education not only 
enhances student skills, even in subjects in which they may express disinterest, but it helps students to develop general skills and apply them to other, perhaps, non-structured learning situations. This approach could be particularly helpful to graduate school students. As Allen Repko (2008) discussed, graduate education that focuses on interdisciplinary research should be done on the basis of common ground. Instructors must cultivate such an environment in the graduate school by encouraging thinking that supports interdisciplinarity; cognitive processes, such as metacognition and critical thinking, encourage students to move beyond myopic research methods to interact with others. As graduate students investigate problems in their own disciplines, they are encouraged to interact with others on the basis of common theories, ideas, or minimally, common end-goals.

However, the ultimate goal of such an approach to interdisciplinary education is to prepare graduate students to apply general skills across multiple disciplines. Such interdisciplinary learning can assist students in making interdisciplinary connections and enhancing general competencies across the span of their learning experiences. Research-driven methods that expand such interdisciplinary skills will ultimately develop students into competent scholars.

\subsubsection{Technology-Integrated versus Technology-Independent}

Finally, research-driven graduate school education should be technology-integrated rather than technology-independent. In other words, technology utilization should be integrated with the instructional process. In a study by Howland \& Weldman (2004), a pre/post-test questionnaire was given to instructors enrolled in professional development courses design to "develop technology knowledge and skill efficacy" and to "integrate technology in teaching" (Howland \& Wedman, 2004, p. 239). Pre-tests were administered to determine the level of technology usage among instructors before a technology utilization course. Post-tests were administered to determine whether or not instructors developed an increased appreciation for technology integration in teaching. Howland \& Weldman assessed these areas of teaching and learning:

1. Technology integration

2. Inquiry-based learning

3. Feedback and metacognition

4. Problem-solving

5. Content knowledge

The following results were reported: "technology integration indicated significant change in inquiry-based learning”, "feedback and metacognition”, "problem-solving”, and "content knowledge" (Howland \& Weldman, 2004, p. 240). Results of the study related to changes instructors made in teaching practices indicated that the instructors "significantly reduced the frequency of lecture" and "integrated problem based learning more frequently". Further, preservice instructors reported using a "variety of technology applications during the courses" (Howland \& Weldman, 2004, p. 246). 
In terms of the intentional integration of technology and instruction, "higher education perhaps posing a greater challenge than many institutions due to disparate faculty interests, high autonomy, and wide variance in technology expertise” (Howland \& Wedman, 2004). However, Gardner, Wissick, Schweder \& Canter (2003) suggested that technology is a meaningful tool by which interdisciplinary education can be enhanced through the thematic unit approach to deep learning. Technology integration, which facilitates the research process and encourages deep learning and critical thinking, should play a central role in graduate school education.

\section{Method}

\subsection{Instrumentation}

The instrumentation of this study included the development of a survey instrument based on the review of literature consisting of sixteen items. The first eight items on the instrument relate directly to the eight categories presented in the review of literature: metacognition versus memorization, critical thinking versus repetition, interdisciplinary versus disciplinary, and technology-integrated versus technology-independent. The second eight items on the instrument relate directly to content versus research in graduate school education. The instrument was designed to be scored by totaling the values in two categories: content-based and research-driven. Each question was presented on a Likert-style scale with a range from 0 (strongly disagree) to 5 (strongly agree). Because the scale consisted of six values, the unambiguous "middle value” was effectively eliminated. Questions were also divided into categories related to attitudes and actualities: survey items categorized as attitudes represent "what should be" and survey items related to actualities represent "what actually is". A list of the survey items and the associated latent variables are included in the appendix. The survey was implemented in an online format.

\subsection{Participants}

Participants included a population of graduate school students and instructors at an accredited graduate school in the United States that primarily serves adult learners. The sample size was 103, 83 of which were graduate students and 20 of which were instructors. The mean age of learners reported by participants was 40-50 years old and the mean age of instructors reported by participants was 50-60 years old. The sample was a sample of the whole. The survey was administered online. Permission to conduct the survey was received by the graduate school's Institutional Review Board equivalent.

\section{Limitations}

The primary limitation of this study was the fact that the sample was drawn from a single institution. Because the sample size was relatively small, it should be interpreted as an empirical case study upon which future research may be conducted.

\section{Research Design}

The research design employed in this study was a split-group comparison design. The survey invitation was sent to all students and instructors. Results were categorized into two groups 
based on the participant's indication of being either a student or an instructor. The two groups were used for comparing statistically significant difference in response to the survey.

\section{Hypotheses}

Three hypotheses were tested by means of statistical analysis. Statistical significance was determined at a critical value of .05 unless otherwise stated. Based on the review of literature, the research hypotheses were as follows:

$\mathbf{H}_{\mathbf{a}} \mathbf{1}$. There was a significant difference in attitudes toward content-based and research-driven graduate school education between instructors and graduate students.

$\mathbf{H}_{\mathbf{a}}$ 2. There was a significant difference in categorical survey items related to attitudes toward research-driven graduate school education between instructors and graduate students.

$\mathbf{H}_{\mathbf{a}}$ 3. There was a significant difference in categorical survey items related to actualities concerning content-based and research-driven instruction between instructors and graduate students.

\section{Null hypotheses}

The null hypotheses were as follows:

$\mathbf{H}_{\mathbf{0}}$ 1. There was no significant difference in attitudes toward content-based and research-driven graduate school education between instructors and graduate students.

$\mathbf{H}_{\mathbf{0}}$ 2. There was no significant difference in categorical survey items related to attitudes toward research-driven graduate school education between instructors and graduate students.

$\mathbf{H}_{0}$ 3. There was no significant difference in categorical survey items related to actualities concerning content-based and research-driven instruction between instructors and graduate students.

\section{Results}

\subsection{Summary Statistics}

Descriptive summary statistics between the two groups: Group 1 as instructors and Group 2 as graduate students revealed relevant details concerning both groups. For these data, $\mathrm{N}=20$ for Group 1 and $\mathrm{N}=83$ for Group 2. The mean age range of Group 1 was 60 or more years old and the mean age range of Group 2 was 40-50 years old. Male participants outnumbered females in the survey responses. Table 1 includes summary statistics for the two groups, including mean scores, standard deviations, minimums, and maximums associated with attitudes toward content-based instruction and research-driven instruction. 
Table 1. Summary Statistics: Group 1: Instructors

\begin{tabular}{|lccccccc|}
\hline Variable & N & MEAN & STD & SEM & MIN & MAX & SUM \\
\hline Age & 20 & 4.50 & 0.95 & 0.21 & 2.00 & 5.00 & 90.00 \\
Gender & 20 & 1.35 & 0.49 & 0.11 & 1.00 & 2.00 & 27.00 \\
Research & 20 & 3.74 & 0.35 & 0.07 & 3.25 & 4.38 & 74.90 \\
Content & 20 & 2.92 & 0.54 & 0.12 & 2.13 & 4.00 & 58.55 \\
Attitudes & 20 & 3.06 & 0.51 & 0.11 & 2.29 & 4.00 & 61.29 \\
Actualities & 20 & 3.54 & 0.36 & 0.08 & 3.00 & 4.44 & 70.89 \\
Summary Statistics: Group 2: Graduate students & & \\
\hline Variable & N & MEAN & STD & SEM & MIN & MAX & SUM \\
\hline Age & 83 & 3.96 & 0.94 & 0.10 & 1.00 & 5.00 & 329.00 \\
Gender & 83 & 1.36 & 0.48 & 0.05 & 1.00 & 2.00 & 113.00 \\
Research & 83 & 3.87 & 0.48 & 0.05 & 1.50 & 4.88 & 321.42 \\
Content & 83 & 3.20 & 0.65 & 0.07 & 1.75 & 5.00 & 265.82 \\
Attitudes & 83 & 3.26 & 0.55 & 0.06 & 2.14 & 4.71 & 271.11 \\
Actualities & 83 & 3.74 & 0.48 & 0.05 & 1.78 & 5.00 & 310.76 \\
\hline
\end{tabular}

\subsection{Age Ranges}

A one-way Analysis of Variance was performed to determine if the average mean value across ranges of age were equal. Age ranges included Age $=1$ (30 years of age or younger), Age $=2$ (Age 31 to 40 ), Age $=3$ (Age 41 to 50 ), Age $=4$ (Age 51 to 60), and Age $=5$ (Greater than 60 years of age).

The average values across categories of Age were not found to be different for the variable Research-Driven, $\mathrm{F}(4,98)=.08, \mathrm{p}=0.99$. For these data, the Mean(SD) of Research-Driven for Age = 1 was 3.92(.0693), $\mathrm{N}=3$, the Mean(SD) of Research-Driven for Age = 2 was 3.9075(.2755), $\mathrm{N}=4$, the Mean(SD) of Research-Driven for Age $=3$ was 3.8507(.7870), $\mathrm{N}=$ 14, the Mean(SD) of Research-Driven for Age $=4$ was 3.8625(.4003), $N=44$, and the Mean(SD) of Research-Driven for Age $=5$ was 3.8176(.4185), $\mathrm{N}=38$. According to these descriptive data, age range for the students or instructors was not associated with their attitudes toward content-based instruction.

The average values across categories of Age were found to be different for the variable Content-Based, $F(4,98)=3.44$, p0.01. A Scheffé multiple comparison procedure was performed at the alpha $=0.05$ significance level to determine specific pairwise differences. For these data, the Mean(SD) of Content-Based for Age $=1$ was 2.9633(.2887), $\mathrm{N}=3$, the Mean(SD) of Content-Based for Age $=2$ was 4.065(.6945), $N=4$, the Mean(SD) of Content-Based for Age $=3$ was 3.0564(.6375), $N=14$, the Mean(SD) of Content-Based for 
Age $=4$ was 2.9993(.6147), $\mathrm{N}=44$, and the Mean(SD) of Content-Based for Age $=5$ was 3.2753(.6073), $\mathrm{N}=38$. According to these descriptive data, age range for the students or instructors was not associated with their attitudes toward research-driven instruction.

\section{$\mathrm{H}_{0} 1$ : Critical Comparison of Content and Research Between Groups}

In a statistical comparison between survey responses of graduate students and instructors toward content-based and research-driven instruction, the means of the two groups were not significantly different, $\mathrm{t}(101)=-1.74, \mathrm{p}=0.085$. For these data, the Mean(SD) of Content-Based for Group 1 (Graduate Students) was 2.9275(.5492), N= 20, and the Mean(SD) of Content-Based for Group 2 (Instructors) was 3.2027(.6534), $\mathrm{N}=83$. The means of the two groups were not significantly different, $\mathrm{t}(101)=-1.11, \mathrm{p}=0.269$. For these data, the Mean(SD) of Research-Driven for Group 1 (Graduate Students) was 3.745(.3507), N= 20, and the Mean(SD) of Research-Driven for Group 2 (Instructors) was 3.8725(.4831), N= 83. The null hypothesis could not be rejected.

\section{$\mathrm{H}_{0}$ 2: Critical Comparison of Attitudes toward Content and Research Between Groups}

In a statistical comparison between the category "attitudes" of graduate students and instructors toward content-based and research-driven instruction, the means of the two groups were not significantly different, $\mathrm{t}(101)=-1.48, \mathrm{p}=0.141$. For these data, the Mean(SD) of Attitudes for Group 1 (Graduate Students) is 3.0645(.5189), $\mathrm{N}=20$, and the Mean(SD) of Attitudes for Group 2 (Instructors) is 3.2664(.5524), $\mathrm{N}=83$. The null hypothesis could not be rejected.

\section{$\mathbf{H}_{0} 3$ : Actualities of Content and Research Between Groups}

In a statistical comparison between the category "actualities" of graduate students and instructors toward content-based and research-driven instruction, the means of the two groups were significantly different, $\mathrm{t}(101)=-1.72, \mathrm{p}=0.045$. For these data, the Mean(SD) of Actualities for Group 1 (Graduate Students) is 3.5445(.3664), $\mathrm{N}=20$, and the Mean(SD) of Actualities for Group 2 (Instructors) is 3.7441(.4873), $\mathrm{N}=83$. The null hypothesis was rejected.

Table 2 contains summary data for the tested null hypotheses, including p-values and significance levels.

Table 2. Summary of Significant Differences between Groups

\begin{tabular}{|lcc|}
\hline Variable & p-Value & Significance \\
\hline Content & 0.085 & - \\
Research & 0.269 & - \\
Attitudes & 0.141 & - \\
Actualities & 0.045 & $* *$ \\
\hline
\end{tabular}




\subsection{Size of the Effect}

For the variable Content-Based, Cohen's $d$ was calculated at -0.30 and the effective size $r$ was calculated at -0.15 . For the variable Research-Based, Cohen's $d$ was calculated at 0.46 and the effective size $r$ was calculated at -0.22 . For the variable Attitudes, Cohen's $d$ was calculated at -0.37 and the effective size $r$ was calculated at -0.18 . For the variable Actualities, Cohen's $d$ was calculated at -0.47 and the effective size $r$ was calculated at -0.22 . For all four variables, the effect size was moderate.

\section{Conclusions}

\subsection{Implications}

Due to the fact that the null hypotheses could not be rejected for $H_{a} 1$ and $H_{a} 2$, the research findings demonstrated that the there were no attitudinal differences between graduate students and instructors concerning content-based and research-driven graduate education. In both cases, content was undervalued when compared to research, but the difference was not statistically significant between the two groups. In the case of actualities, the difference between "what actually is" and "what should be" was statistically significant between graduate students and instructors. Graduate students identified that what they expect is not necessarily what is being provided in their courses, especially in relation to course materials and the classroom. Therefore, the issue of critical importance to instructors is to determine why there is disconnection between what they agree adults need and what actually occurs in the educational process. Instructors must intentionally seek to provide opportunities for deep learning with an emphasis on research-driven instruction.

Designing research-driven instruction is a viable enterprise for graduate school instructors. Instructors should maintain the goal of helping students ask questions of themselves as they are learning and to "help them establish habits for continually using a deep approach to learning” (Wilson-Smith \& Colby, 2007, p. 106). Using the carefully constructed taxonomies, instructors can evaluate whether surface or deep learning is occurring (Wilson-Smith \& Colby, 2007, p. 107) and thus, whether content or research is the focus of learning. Assessment must be an intrinsic part of the learning process, not only to determine if learning has occurred, but also to continually revise and improve the learning process (Wilson-Smith \& Colby, 2007, p. 107). According to Bruce \& Bishop (2002), professors are also learners in the research-driven approach because they must communicate with their colleagues and construct new pathways to research-driven instruction. When a research-driven approach to instruction is intentionally implemented, graduate school students and instructors both benefit because they both participate in the learning process; they are, in effect, "co-creators" of the learning process.

\subsection{Future Research}

Future research should be expanded to include a much larger population across multiple graduate schools. The small sample size was the primary limitation of this case study. Because of the small sample size, findings cannot be generalized. However, this empirical case study consisted of preliminary research into the problem of how graduate students view 
their educational experience in graduate school and what reforms they desire to see in the future. Future researchers may utilize these findings to broaden investigations.

\section{References}

Billett, S. (2004). Co-participation at work: learning through work and throughout social lives, in Studies in the Education of Adults, 36(2), 190-205. http://www.ingentaconnect.com/content/niace/stea/2004/00000036/00000002/art00004

Bolkan, S. \& Goodboy, A. (2009). Transformational leadership in the classroom: fostering student learning, student participation, and teacher credibility. Journal of Instructional Psychology, 36(4). http://dx.doi.org/10.1080/08824096.2011.615958.

Bruce, B. C., \& Bishop, A. P. (2002). Using the Web to Support Inquiry-Based Literacy Development. Journal of Adolescent \& Adult Literacy, 45(8), 706+. Retrieved September 5, 2010, from Questia database: http://www.questia.com/PM.qst?a=o\&d=5000762697

Burns, J. (1978). Leadership. New York, NY: Harper Collins.

Cranton, p. (1994). Self-directed and transformative instructional development. Journal of Higher Education, 65(6), 726+. Retrieved September 5, 2010, from Questia database: http://www.questia.com/PM.qst?a=o\&d=5000290903

Donlevy, J. (1998). Teachers, technology, and training: adult education: a brief review of literature using a template of perspectives. International Journal of Instructional Media, 25(1). Retrieved September 10, 2010, from Questia database: http://www.questia.com/googleScholar.qst?docId=5001393768

Gardner, J. E., Wissick, C. A., Schweder, W., \& Canter, L. S. (2003). Enhancing interdisciplinary instruction in general and special education: Thematic units and technology. Remedial and Special Education, 24(3), 161+. Retrieved September 13, 2010, from Questia database: http://www.questia.com/PM.qst?a=o\&d=5001937158

Howland, J., \& Wedman, J. (2004). A process model for faculty development: Individualizing technology learning. Journal of Technology and Teacher Education, 12(2), 239+. Retrieved September 5, 2010, from Questia database: http://www.questia.com/PM.qst?a=o\&d=5007672373

Jerram, C. (2003). Applying adult education principles to university teaching. University of Western Sydney, Australia.

Knowles, M. (1984). Andragogy in action: Applying modern principles of adult education. San Francisco, CA: Jossey Bass.

Manheimer, R. J. (2008). Lifelong learning in aging societies: Emerging paradigms. Annual Review of Gerontology \& Geriatrics, January, 2008. 111+. Retrieved September 5, 2010, from Questia database: http://www.questia.com/PM.qst?a=o\&d=5035127603

Marton, F. \& Säljö,R. (1976). On qualitative differences in learning 1: Outcome and process. British Journal of Educational Psychology 46, 4-11. 
Nilson, L. (2010). Teaching at its best: a research-driven resource for college instructors. San Francisco, CA: Jossey Bass.

Reid, I. (1978). Sociological perspectives on school and education. Open Books Publishing: London, UK.

Repko, A. (2008). Interdisciplinary Research: Process and Theory. Thousand Oaks, CA: SAGE Publications.

Willingham, D. (2007). Critical thinking: Why is it so hard to teach? American Educator, 109(4), 8-19. http://dx.doi.org/10.3200/AEPR.109.4.21-32.

Wilson Smith, T., \& Colby, S. (2007). Teaching for Deep Learning. The Clearing House, 80(5), 205-210. http://dx.doi.org/10.3200/TCHS.80.5.205-210 


\section{Appendix 1}

\begin{tabular}{|c|c|c|c|}
\hline Group & Category & $\begin{array}{l}\text { Conceptual } \\
\text { Framework }\end{array}$ & Survey Item \\
\hline $\mathrm{AT}$ & Research & Metacognition & $\begin{array}{l}\text { When approaching new information, it is important } \\
\text { to first consciously consider how to think about such } \\
\text { information. }\end{array}$ \\
\hline AT & Content & Memorization & $\begin{array}{l}\text { In order for learning to be successful, it is important } \\
\text { to memorize certain information. }\end{array}$ \\
\hline $\mathrm{AT}$ & Research & Critical Thinking & $\begin{array}{l}\text { It is more important to critically analyze information } \\
\text { than to be able to recall it later. }\end{array}$ \\
\hline $\mathrm{AT}$ & Content & Repetition & $\begin{array}{l}\text { Learning has occurred when facts and information } \\
\text { are able to be recalled from memory. }\end{array}$ \\
\hline AT & Research & Interdisciplinary & $\begin{array}{l}\text { Adults should be able to generalize information } \\
\text { rather than specialize on specific content. }\end{array}$ \\
\hline $\mathrm{AC}$ & Content & Disciplinary & $\begin{array}{l}\text { Specific information should be the focus for each } \\
\text { course or subject that is taught. }\end{array}$ \\
\hline $\mathrm{AC}$ & Research & $\begin{array}{l}\text { Technology-Orie } \\
\text { nted }\end{array}$ & $\begin{array}{l}\text { Because so much information is available, } \\
\text { technology facilitates inquiry and learning. }\end{array}$ \\
\hline $\mathrm{AC}$ & Content & $\begin{array}{l}\text { Technology-Inde } \\
\text { pendent }\end{array}$ & $\begin{array}{l}\text { The classroom lecture is of central importance in } \\
\text { adult learning. }\end{array}$ \\
\hline $\mathrm{AC}$ & Content & Content-based & $\begin{array}{l}\text { The course syllabi contain information relevant to my } \\
\text { needs. }\end{array}$ \\
\hline $\mathrm{AC}$ & Research & Research-driven & $\begin{array}{l}\text { Course syllabi should provide a basic framework by } \\
\text { which learning is guided. }\end{array}$ \\
\hline $\mathrm{AC}$ & Content & Content-based & $\begin{array}{l}\text { Course content should be pre-determined as } \\
\text { appropriate information for learning. }\end{array}$ \\
\hline $\mathrm{AC}$ & Research & Research-driven & $\begin{array}{l}\text { Course content should be minimal, allowing adult } \\
\text { learners to research within a framework. }\end{array}$ \\
\hline $\mathrm{AT}$ & Content & Content-based & $\begin{array}{l}\text { Adult learners need a professor to tell them what they } \\
\text { need to know. }\end{array}$ \\
\hline $\mathrm{AC}$ & Research & Research-driven & $\begin{array}{l}\text { Adult learners can find solutions to problems and } \\
\text { information relevant to their needs. }\end{array}$ \\
\hline AT & Content & Content-based & $\begin{array}{l}\text { Professors should determine what students need to } \\
\text { know. }\end{array}$ \\
\hline $\mathrm{AC}$ & Research & Research-driven & $\begin{array}{l}\text { Adult learners can determine what they need to know } \\
\text { and find it. }\end{array}$ \\
\hline
\end{tabular}

